\title{
Leptospira infections in freshwater fish in Morogoro Tanzania: a hidden public health threat
}

\author{
GEORGIES F. MGODE ${ }^{1 *}$, GINETHON G. MHAMPHI ${ }^{1}$, ABDUL S. KATAKWEBA ${ }^{1}$ and MICHAEL THOMAS ${ }^{2}$ \\ ${ }^{1}$ Pest Management Centre, Sokoine University of Agriculture, P.O. Box 3110, Morogoro, Tanzania \\ ${ }^{2}$ Department of Wildlife Management, Sokoine University of Agriculture, Morogoro, Tanzania
}

\begin{abstract}
Leptospirosis caused by spirochete bacterium of genus Leptospira affects humans and animals worldwide. Rodents are major reservoirs of leptospires whereas wetland and aquatic migratory birds also carry and transmit leptospires. Leptospirosis studies in fish are lacking in African countries despite favourable environment and abundant reservoirs, which can spread leptospires into aquatic habitats and infect fish. The objectives of this study were to determine presence of Leptospira in fish; the prevalent Leptospira serovars and whether are related to serovars reported in animals; and to ascertain potential public health risk. Live tilapia, catfish and eel fish $(n=48)$ were caught in Mindu Dam in Morogoro Municipality in eastern Tanzania. Blood sample was collected using syringes and needles to obtain serum for serological detection of leptospirosis using gold standard microagglutination test utilizing local and reference Leptospira serovars Sokoine, Kenya, Pomona and Hebdomadis. Twenty-six fish (54.2\%) were positive for serovar Kenya (29.2\%) and Sokoine (25\%). Leptospira prevalence was high in both catfish (58.3\%) and tilapia fish (47.8\%). Thus, different fish types are infected with Leptospira found in animals. Fish could be source of Leptospira infection to humans since tilapia and catfish are the common fish type widely consumed in Tanzania. Further study covering lakes, rivers and dams is required to better understand the prevalence of Leptospira in fish and actual public health threats.
\end{abstract}

Keywords: Leptospirosis, zoonosis, freshwater fish, Tanzania

\section{Introduction}

Leptospirosis is a zoonotic disease caused by spirochete bacterium of the genus Leptospira that affect humans and animals worldwide (Bharti et al., 2003; Pappas et al., 2008; WHO, 2011). Rodents are major reservoirs of Leptospira bacteria (Babudieri, 1958). Other wild animals and birds found in wetland areas may also carry and disseminate leptospires into the environment (Galton, 1959; Addamiano et al., 1960). Leptospires can live longer in water and moist soil with pH 6-8 and have the ability to form biofilms during interaction with environmental bacteria (Barragan et al., 2011). There are pathogenic, saprophytic and intermediary leptospires found in natural environment and animals hosts (Faine et al., 1999; Mgode et al., 2010). Humans get leptospirosis through contaminated environment and /or direct contact with infectious materials such as urine and blood from infected animal. The disease is associated with certain occupational activities such as rice and sugarcane farming, fishing and fish farming, livestock keeping, handling animal products and water sports (Waitkins, 1986; Cutler et al., 2010). Clinical symptoms of leptospirosis in humans are variable (Faine, 1982), and may be mistaken with other diseases including malaria.

Leptospirosis is widely distributed in African continent that has the highest burden on global scale (WHO, 2011). The disease has been reported in humans in Gabon (Bertherat et al., 1999), in small mammals from Benin (Houemenou et al., 2013) and in rodents and buffalos in Kenya and Uganda (Halliday et al., 2013; Atherstone et al., 2013). In Tanzania, leptospirosis has been widely reported with high prevalence in rodents, cattle, dogs, pigs, and recently in bats (Machang'u et al., 1997; Mgode et al., 2005; Ahmed et al., 2006; Mgode et al., 2006; Schoonman, 2007; Schoonman \& Swai, 2010; Kessy et al., 2010; Mgode et al., 2014). In human, a prevalence of leptospirosis of $17.5 \%$ has been reported in Morogoro in eastern Tanzania (Machang'u, 2006) and

\footnotetext{
* Correspondence: Georgies F. Mgode; Email: gmgode@suanet.ac.tz
} 
nine percent of hospitalized people with non-malarial fevers in northern Tanzania (Biggs et al., 2011).

The high prevalence of leptospirosis in various animal hosts and humans in Africa and in Tanzania in particular, suggest that this disease could be abundant in aquatic hosts such as freshwater fish, which could maintain the pathogens and disseminate to humans. Few studies in Europe have reported leptospirosis in fish and fish farmers (Maestrone \& Benjaminson, 1962; Robertson et al., 1981; Barragan et al., 2011). Human leptospirosis cases associated with freshwater environment especially stagnant water and fish pond areas have been reported in Serbia (Svirčev et al., 2009). Such studies are lacking in Tanzania and other African countries with favourable environment for maintenance and dissemination of leptospirosis. The objectives of this study were to determine presence of Leptospira in freshwater fish in Mindu dam, Morogoro municipality and to establish local Leptospira serovars for assessing relatedness with local serovars found in the area. The study also aimed at obtaining information for promoting public awareness of the neglected zoonotic disease since fishing and extensive agricultural activities are undertaken around Mindu dam areas. People living around the dam often swim in this dam hence are likely to get infected with leptospirosis.

\section{Materials and Methods}

\section{Study site description}

Mindu dam on Ngerengere River is located $10 \mathrm{~km}$ from Morogoro Municipality along MorogoroIringa highway in eastern Tanzania. It is a man made dam supplying $80 \%$ of water in the municipality including Sangasanga and Kasanga villages located less than a kilometre away from the dam. The dam gathers water from the Uluguru mountain ranges. Crop farming and fishing are major socio-economic activities around the dam.

\section{Fish samples and leptospiral antibodies detection}

Live fish $(\mathrm{N}=48)$ caught in Mindu dam by fishermen in May 2003 were randomly collected for serological detection of leptospiral antibodies using microscopic agglutination test (MAT). MAT is the gold standard test for diagnosis of leptospirosis. It detects antibodies against specific causative Leptospira serovars with limited ability to also detect antibodies against closely related serovars. Three types of fish, namely Tilapia, Catfish and Eel fishes were obtained from the dam. Tilapia and catfish were the predominant species, which are also commonly found in local freshwater fish market. Number of samples per fish type was: Tilapia spp. $(n=23)$, Catfish $(n=24)$ and Eel fish $(n=1)$. Blood was collected from fish using syringes and needles, and serum separated from blood by centrifugation. Sera were stored in freezer at $-20^{\circ} \mathrm{C}$ until used in microagglutination test for serodiagnosis of leptospirosis as previously described (Cole et al., 1973; Goris \& Hartskeerl, 2013). Briefly, local Leptospira serovars isolated from animals in Tanzania, namely Leptospira serovar Sokoine and serovar Kenya mainly found in domestic animals and rodents were selected for use in MAT. Others serovars were reference Leptospira serovar Pomona and Hebdomad is also previously reported in animals in Tanzania. These serovars were cultured into fresh Leptospira EMJH (Ellinghausen and McCullough, modified by Johnson and Harris) culture medium incubated at $30^{\circ} \mathrm{C}$ for 4 to 7 days before using as live antigen in MAT. Culture purity and density was checked using darkfield microscope whereby a density of $300 \times 10^{8}$ leptospires/ml was considered adequate for MAT. Fish serum samples were serially diluted to 1:10 - 1:80 with phosphate buffered saline $(\mathrm{pH} 7)$ in $\mathrm{U}$-bottomed microtitre plate to $50 \mu \mathrm{l}$ total volumes. Live leptospires antigen $(50 \mu \mathrm{l})$ was added to diluted serum to give final dilutions of 1:20 $-1: 160(100 \mu \mathrm{l}$ total volume) of serum-antigen mixture. The plates with serum-antigen mixture were incubated at $30^{\circ} \mathrm{C}$ for $2-4$ hours before examining for agglutination of leptospires and antibodies under darkfield microscope. 


\section{Ethical considerations}

Live fish were handled in compliance with the Animal Research: Reporting in Vivo Experiments guidelines and the Helsinki Declaration.

\section{Results}

A total of 48 fishes were screened for leptospirosis using 4 live Leptospira serovars. Twenty-six fish (54.2\%) were seropositive reacting with Leptospira serovar Kenya, serovar Sokoine and Pomona. Seropositive fish samples belonged to all three types of fish (tilapia, catfish and eel fish). The proportion of seropositivity of the three fish types is presented in Table 1.

Table 1: Leptospiral positive samples in 3 types of fish from Mindu dam, Morogoro

\begin{tabular}{lllll}
\hline Fish type & Samples tested $(\mathbf{n})$ & Positive & Negative & Leptospirosis prevalence per fish type \\
\hline Tilapia & 23 & 11 & 12 & $47.8 \%$ \\
Catfish & 24 & 14 & 10 & $58.3 \%$ \\
Eel fish & 1 & 1 & 0 & $100 \%$ \\
\hline
\end{tabular}

The prevalent Leptospira serovars were serovar Kenya (29.2\%), serovar Sokoine (25\%), whereas serovar Pomona reacted with lower titres $(1: 20)$ in tilapia fish $(n=1)$ and catfish $(n=2)$ samples which were also positive for serovar Sokoine and Kenya with relatively higher titres (1:40 and 1:80). The average agglutination titres across fish types for two most reacting Leptospira serovars were 1:40 and 1:80. Leptospira serovar Hebdomadis was not detected in the fish samples (Table 2). Leptospira serovar Sokoine was detected in all three types of fish whereas serovar Kenya was detected in catfish and tilapia fish only.

Table 2: Prevalence of Leptospira serovars in 3 types of fish from Mindu dam, Morogoro

\begin{tabular}{llllll}
\hline Fish type & Samples $(\mathbf{n})$ & Sokoine & Kenya & Pomona & Hebdomadis \\
\hline Tilapia fish & 23 & 3 & 8 & $1^{*}$ & 0 \\
Catfish & 24 & 8 & 6 & $2^{*}$ & 0 \\
Eel fish & 1 & 1 & 0 & 0 & 0 \\
Total & 48 & 12 & 14 & 3 & 0 \\
\hline Leptospira serovar prevalence & $25 \%$ & $29.2 \%$ & $6.3 \%$ & \\
\hline * Three specimens that reacted with serovar Pomona & were also positive for serovar Sokoine (2) and Kenya (1) \\
suggesting cross-reaction
\end{tabular}

Leptospirosis prevalence was high in both catfish and tilapia types whereby 14 of the 24 tested catfish were leptospirosis positive (58.3\%) and 11 tilapia out of 23 were positive (47.8\%). The prevalence of leptospirosis in the two common fish types was relatively similar (Figure 1) with no statistical significant difference ( $p=0.56$, Fisher's exact test). An eel fish was also seropositive.

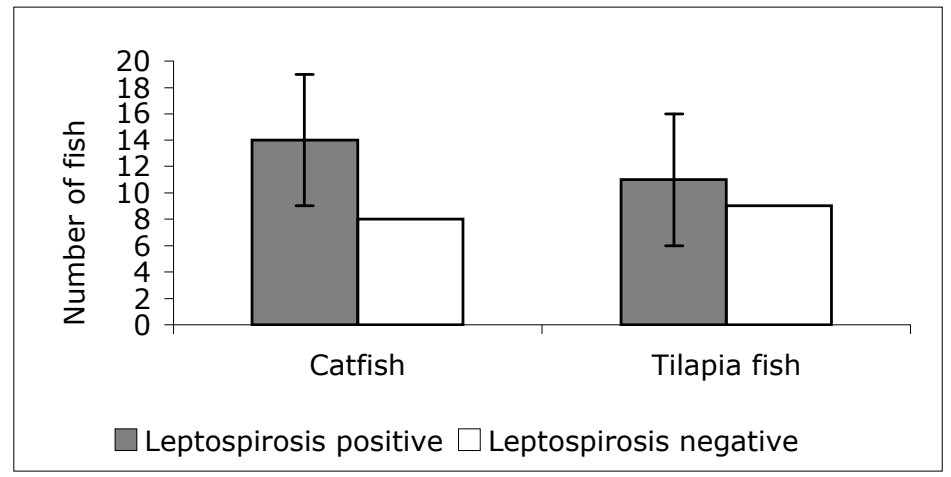

Figure 2: Leptospira in catfish and tilapia from Mindu dam 
Leptospira serovar Kenya was detected in 14 fish samples out of 48 (29.2\%) consisting of 8 tilapia fish and 6 catfish. Serovar Sokoine was detected in 12 of the 48 fish (25\%) consisting of 8 catfish, 3 tilapia fish and an eel fish.

\section{Discussion}

This study reveals a high prevalence of pathogenic leptospires in three types of freshwater fish found in Mindu dam in Morogoro municipality. This is the first report on Leptospira in fish in Tanzania and Africa. A prevalence of $54.3 \%$ observed in common fish types largely consumed by people in this region suggest potential public health threat especially due to lack of public awareness of leptospirosis in Tanzania. People engaged with rice farming and cultivating vegetables around Mindu dam catchments area have high risk of contracting this disease as it is reported elsewhere (Waitkins, 1986; Cutler et al., 2010). Other vulnerable groups include sugarcane farmers, fishermen, fresh-fish traders, swimmers and other individuals with direct and/or indirect contact with wet environment contaminated with leptospires from infected animals. Worker in these environments requires protective gears to prevent infection.

Local Leptospira serovars Kenya and Sokoine that are the predominant serovars in rodents and cattle in Tanzania (Machang'u et al., 2004; Mgode et al., 2006) are also the predominant serovars in tilapia and catfish species. This indicates relatedness or sharing of Leptospira pathogens between terrestrial mammals such as rodents and cattle; and aquatic living organisms like fish found in same locality. Identification of the point source of the widely circulating Leptospira serovars such as Sokoine found in broad range of species is necessary. This is possible through isolation in various hosts including fish and assessing the phylogenetic status of isolates. The point source or hosts that are major transmitter of leptospirosis could be targeted in control strategies.

The prevalence of leptospirosis in fish is higher exceeding the prevalence of leptospirosis in terrestrial animals such as cattle and rodents in Morogoro, which range from 10 to $20 \%$ (Machang'u, 2006). However, the higher prevalence of Leptospira in this study is likely to be dues to the small sample of fish. Leptospira infection is high across freshwater fish types. Leptospira infection rate in different fish types (catfish and tilapia) was similar for two reacting serovars Kenya and Sokoine suggest that there is no host-specificity. A single eel fish captured in this dam was also seropositive. Although this study reports on fish specimens from a single dam, its findings may reflect the leptospirosis burden in other freshwater bodies found in Tanzania and the great lakes region of east and central Africa. Further studies with large sample size and geographic coverage, which includes Lake Tanganyika, Lake Victoria, Lake Nyasa, Lake Rukwa, Mtera and Nyumba ya Mungu dams and rivers which are the major source tilapia and catfish consumed in Tanzania is required to determine the extent of potential human and animal health risks. Isolation of Leptospira bacterium is needed for understanding the infecting serovars, which can be included in serodiagnosis of leptospirosis in humans and animals. The reported diversity of reservoir hosts of leptospirosis in Tanzania, namely rodents, bats, domestic animals (Machang'u et al., 1997; Machang'u et al., 2004; Mgode et al., 2006, 2014) and the present report of Leptospira in fish indicate an urgent need for increasing public awareness of this emerging zoonotic disease in the country. Lack of awareness puts the vulnerable human populations engaged in irrigation farming, fishing, fish farming, livestock keeping and swimming in fresh water at high health risk.

Limitation of this study was minimal because incorporation of more Leptospira serovars including local serovars overcame the weakness of MAT of failing to detect serovars not included. Serovars for inclusion in MAT were carefully selected and demonstrated robustness of MAT in diagnosis of leptospirosis in diverse host species. However, the need for live Leptospira in MAT as antigen is limiting factor for application of this gold standard test in resource poor countries, which have highest burden in the world (WHO, 2011). Usefulness of MAT can be 
strengthened by isolation and identification of Leptospira from different hosts and incorporation of the new isolates in the serodiagnosis of leptospirosis in humans and animals.

In conclusion this study shows high Leptospira infection in common freshwater fish types largely consumed by people hence indicate public health risk. To prevent or reduce leptospirosis transmission in Tanzania where the disease is largely unknown and neglected, it is recommended (i) To increase public awareness of leptospirosis to avoid its health risks. Health workers and the general public particularly those risk groups such as farmers, livestock keepers, fishermen, sewerage workers, and abattoir workers should be made aware of leptospirosis; (ii) Routine Leptospirosis diagnosis should be considered in people engaged with occupational activities that increase contact with environments likely to contain leptospires especially when malaria, typhoid fever, and dengue fever are ruled out; and (iii) Isolation of leptospires from different hosts and sources should be prioritised in order to understand the sources of infections, infecting serovars and developing a panel of serovars for use in serodiagnosis of this disease particular areas or region.

\section{Acknowledgements}

We acknowledge the logistical assistance by the Sokoine University of Agriculture Pest Management Centre.

\section{References}

Addamiano, L., Babudieri, B., Bussinello, E., Giusti, G. \& Salvi, A. (1960) Research and experimental studies on leptospirosis in birds. Rendiconti dell'Istituto Superiore di Sanita 23, 482-96.

Ahmed, N., Devi, S.M., Valverde Mde, L., Vijayachari, P., Machang'u, R.S., Ellis, W.A. \& Hartskeerl, R.A. (2006) Multilocus sequence typing method for identification and genotypic classification of pathogenic Leptospira species. Annals of Clinical Microbiology and Antimicrobials 5, 28.

Atherstone, C., Picozzi, K. \& Kalema-Zikusoka, G. (2013) Seroprevalence of Leptospira Hardjo in Cattle and African Buffalos in Southwestern Uganda. American Journal of Tropical Medicine and Hygiene 90:288-290.

Babudieri, B. (1958) Animal reservoirs of leptospires. Annals of New York Academy of Sciences 70, 393-413.

Barragan, V.A., Mejia, M.E., Trávez, A., Zapata, S., Hartskeerl, R.A., Haake, D.A. \& Trueba, G.A. (2011) Interactions of Leptospira with environmental bacteria from surface water. Current Microbiology 62, 1802-1806.

Bertherat, E., Renaut, A., Nabias, R., Dubreuil, G. \& Georges-Courbot, M.C. (1999) Leptospirosis and Ebola virus infection in five gold-panning villages in northeastern Gabon. American Journal of Tropical Medicine and Hygiene 60, 610-615.

Bharti, A.R., Nally, J.E., Ricaldi, J.N., Matthias, M.A., Diaz, M.M., Lovett, M.A., Levett, P.N., Gilman, R.H., Willig, M.R., Gotuzzo, E. \& Vinetz, J.M. (2003) Leptospirosis: a zoonotic disease of global importance. Lancet Infectious Diseases 3, 757-771.

Biggs, H.M., Bui, D.M., Galloway, R.L., Stoddard, R.A., Shadomy, S.V., Morrissey, A.B., Bartlett, J.A., Onyango, J.J., Maro, V.P., Kinabo, G.D., Saganda, W. \& Crump, J.A. (2011) Leptospirosis among hospitalized febrile patients in northern Tanzania. American Journal of Tropical Medicine and Hygiene 85, 275.

Cole, J.R., Sulzer, C.R. \& Pursell, A.R. (1973) Improved microtechnique for the leptospiral agglutination test. Applied Microbiology 25, 976-980.

Cutler, S.J., Fooks, A.R. \& Van Der Poel, W.H. (2010) Public health threat of new, re-emerging and neglected zoonoses in the industrialized world. Emerging Infectious Diseases 16, 1. 
Faine, S. (Ed.) (1982) Guidelines for the Control of Leptospirosis. World Health Organization, Geneva.

Faine, S., Adler, B., Bolin, C. \& Perolat, P. (1999) Leptospira and Leptospirosis. Melbourne: MediSci.

Galton, M.M. (1959) The epidemiology of leptospirosis in the United States with special reference to wild animal reservoirs. Southwestern Veterinarian 13, 37-42.

Goris, M.G. \& Hartskeerl, R.A. (2013) Leptospirosis serodiagnosis by the microscopic agglutination test. Current Protocols in Microbiology $12 \mathrm{E}-5$.

Halliday, J.E., Knobel, D.L., Allan, K.J., de C Bronsvoort, B.M., Handel, I., Agwanda, B., Cutler, S.J., Olack, B., Ahmed, A., Hartskeerl, R.A., Njenga, M.K., Cleaveland, S. \& Breiman, R.F. (2013) Urban leptospirosis in Africa: a cross-sectional survey of Leptospira infection in rodents in the Kibera urban settlement, Nairobi, Kenya. American Journal of Tropical Medicine and Hygiene 89, 1095.

Houemenou, G., Ahmed, A., Libois, R. \& Hartskeerl, R.A. (2013) Leptospira spp. prevalence in small mammal populations in Cotonou, Benin. ISRN Epidemiology 2003.

Kessy, M.J, Machang'u, R.S. \& Swai, E.S. (2010) A microbiological and serological study of leptospirosis among pigs in the Morogoro municipality, Tanzania. Tropical Animal Health and Production 42, 523-530.

Machang'u, R. (2006) Rodent and human disease in Tanzania. RatZooMan Workshop 3-6 May 2006, Malelane, Republic of South Africa, pp 26-27.

Machang'u, R.S., Mgode, G. \& Mpanduji, D. (1997) Leptospirosis in animals and humans in selected areas of Tanzania. Belgian Journal of Zoology 127, 97-104.

Machang'u, R.S., Mgode, G.F., Assenga, J., Mhamphi, G., Weetjens, B., Cox, C., Verhagen, R., Sondij, S., Goris, M.G. \& Hartskeerl, R.A. (2004) Serological and molecular characterization of Leptospira serovar Kenya from captive African giant pouched rats (Cricetomys gambianus) from Morogoro Tanzania. FEMS Immunology and Medical Microbiology 41, 117121.

Maestrone, G. \& Benjaminson, M.A. (1962) Leptospira infection in the gold fish (Carassius auratus). Nature 195, 719-720.

Mgode, G.F., Machang'u, R.S., Collares-Pereira, M., Vieira, M.L., Goris, M.G.A., Engelbert, M. \& Hartskeerl, R.A. (2010) Challenges in determining the pathogenicity status of Leptospira isolates with phenotypic methods: The need for a polyvalent approach. African Journal of Microbiology Research 4, 2528-2533.

Mgode, G.F., Machang'u, R.S., Goris, M.G., Engelbert, M., Sondij, S. \& Hartskeerl, R.A. (2006) New Leptospira serovar Sokoine of serogroup Icterohaemorrhagiae from cattle in Tanzania. International Journal of Systematic and Evolutionary Microbiology 56, 593-597.

Mgode, G.F., Mbugi, H.A., Mhamphi, G.G., Ndanga, D. \& Nkwama, E.L. (2014) Seroprevalence of Leptospira infection in bats roosting in human settlements in Morogoro municipality in Tanzania. Tanzania Journal of Health Research 16 (1).

Mgode, G.F., Mhamphi, G., Katakweba, A., Paemelaere, E., Willekens, N., Leirs, H., Machang'u, R.S. \& Hartskeerl, R.A. (2005) PCR detection of Leptospira DNA in rodents and insectivores from Tanzania. Belgian Journal of Zoology 135, 17-19.

Pappas, G., Papadimitriou, P., Siozopoulou, V., Christou, L. \& Akritidis, N. (2008) The globalization of leptospirosis: worldwide incidence trends. International Journal of Infectious Diseases 12, 351-357.

Robertson, M.H., Clarke, I., Coghlan, J. \& Gill, O.N. (1981) Leptospirosis in trout farmers. Lancet 318, 626-627.

Schoonman, L. \& Swai, E.S. (2010) Herd-and animal-level risk factors for bovine leptospirosis in Tanga region of Tanzania. Tropical Animal Health and Production 42, 1565-1572.

Schoonman, L. (2007) Epidemiology of leptospirosis and other zoonotic diseases in cattle in Tanzania and their relative risk to public health. Doctoral dissertation, Reading University. 
Svirčev, Z., Marković, S.B., Vukadinov, J., Stefan-Mikić, S., Ruzić, M., Doder, R., Fabri, M., Canak, G., Turkulov, V., Stojanović, D.B. \& Draganić, M. (2009) Leptospirosis distribution related to freshwater habitats in the Vojvodina region (Republic of Serbia). Science in China, Series C: Life Sciences 52, 965-971.

Waitkins, S.A. (1986) Leptospirosis as an occupational disease. British Journal of Industrial Medicine 43, 721.

WHO (2011) Report of the Second Meeting of Leptospirosis Burden Epidemiology Reference Group. World Health Organization, Geneva, Switzerland. 